\title{
Ontogenic changes in hepatic glutathione and metallothionein in rats and the effect of a low-sulphur-containing diet
}

\author{
BY MISAKO TANIGUCHI \\ Department of Food and Nutrition, Nakamura Gakuen College, Jonan-Ku, Fukuoka 814, Japan \\ AND M. GEORGE CHERIAN* \\ Department of Pathology, University of Western Ontario, London, Ontario N6 A 5Cl, Canada
}

(Received 21 February 1989 - Accepted 2 August 1989)

\begin{abstract}
Metallothionein contains about $30 \%$ cysteine and is a major protein in newborn rat liver. This protein and glutathione constitute two major intracellular cysteine pools in newborn rat liver. When pregnant rats were fed on a soya-bean-protein diet, low in sulphur amino acids, the hepatic glutathione levels of the dams were decreased. However, this did not affect the levels of glutathione or metallothionein in the pups. The activity of the glutathione-degrading enzyme $\gamma$-glutamyltransferase $(E C 2.3 .2 .2)$ in the livers of pups was maximum at birth and gradually decreased with age when the hepatic glutathione was transported to the kidney. In the pups born from dams fed on soya-bean-protein diet the decline in the hepatic enzyme activity was delayed, suggesting a continued degradation of glutathione in the liver. These results suggest that even with a maternal nutritional deficiency of sulphur amino acids, the transfer of cysteine to the fetus is not impaired. However, the hepatic intra-organ degradation of glutathione is continued in these pups for a prolonged period after birth compared with pups born from control mothers. The increased degradation of glutathione in the liver may be essential to meet the requirement of cysteine in pups born from dams fed on the soya-bean-protein diet.
\end{abstract}

Glutathione: Metallothionein: Sulphur metabolism: Rat

The intracellular hepatic levels of cysteine and glutathione (GSH) in rats during development are regulated by various factors such as the transfer of nutrients from the dams and the ability of the fetal-neonatal liver to convert methionine to cysteine by the trans-sulphuration pathway (Heinonen, 1973; Tateishi et al. 1974, 1977; Kaplowitz et al. 1985; States et al. 1987). Although the activity of cystathionine $\gamma$-lyase (cystathionase; EC 4.4.1.1) is low in human fetal liver, high activity of this enzyme is reported in rat liver during development (Gaull et al. 1972; Heinonen, 1973; Zlotkin \& Anderson, 1982). Thus, cysteine can be formed actively from methionine in fetal rat liver. In addition to GSH, which is considered as a cysteine reservoir, fetal-neonatal rat liver also contains high levels of metallothionein (MT), a protein with a high cysteine content (Bell, 1979; Wong \& Klaassen, 1979; Panemangalore et al. 1983; Templeton et al. 1985). The exact source of cysteine for the synthesis of MT in the fetal liver is not known.

The transfer of zinc from dams to the fetus has a marked effect on the hepatic MT levels in newborn rats. When the pregnant rats were fed on a $\mathrm{Zn}$-deficient diet from day 14 of gestation, the hepatic MT and Zn levels in the neonates were decreased without any change in GSH levels (Gallant \& Cherian, 1986; Andrews et al. 1987). The first step in GSH hydrolysis is catalysed by the enzyme $\gamma$-glutamyltransferase (EC 2.3.2.2; GGT) and the cysteine moiety may be re-utilized after further degradation of cysteinylglycine (McIntyre \& Curthoys, 1979; Inoue \& Morino, 1981). The activity of hepatic GGT in adult rodents 
Table 1. Composition of the soya-bean-protein diet* $(\mathrm{g} / \mathrm{kg})$

$\begin{array}{lc}\text { Ingredient } & \\ \text { Soya-protein isolate } \nmid & 100 \\ \text { Dextrin } & 768 \\ \text { Cellulose powder } & 20 \\ \text { Mineral mixture } \ddagger & 50 \\ \text { Vitamin mixture } \ddagger & 10 \\ \text { Choline chloride } & 1 \\ \text { Maize oil } & 50\end{array}$

* The soya-bean-protein diet differed from the control diet (Purina chow) mainly in its protein ( $100 \mathrm{~g} / \mathrm{kg})$ and sulphur amino acid content. The total protein content of the control diet was $200 \mathrm{~g} / \mathrm{kg}$ and the sulphur amino acid contents were about 0.32 and $0.43 \mathrm{~g} / \mathrm{kg}$ for cystine and methionine respectively, compared with $0.12 \mathrm{and} 0.13 \mathrm{~g} / \mathrm{kg}$ for the soya-bean-protein diet

$\dagger$ Soya-bean-protein isolate $(911 \mathrm{~g}$ crude protein $($ nitrogen $\times 6.25) / \mathrm{kg}$ ) was obtained from Fuji Seiyu Co., Osaka, Japan. The essential amino acid content $(\mathrm{g} / \mathrm{l} 6 \mathrm{gN})$ of soya-protein isolate (Fujipro-R) was as follows: valine $5 \cdot \mathrm{I}(78)$, leucine $8 \cdot 0(96)$, isoleucine $5 \cdot 1(92)$, lysine $6 \cdot 5(84)$, threonine $3 \cdot 8(70)$, tyrosine $4 \cdot 2$ and phenylalanine $5 \cdot 3(109)$, tryptophan $1 \cdot 3(87)$, methionine 1.4 and cystine $1 \cdot 3(41)$, histidine $2 \cdot 6(80)$, arginine $8 \cdot 1$ (111). (The values in parentheses are percentage of amino acid content compared with the control Purina rat chow used in the study.)

$\ddagger$ Both the mineral and vitamin mixtures of the Rogers \& Harper (1965) formula were obtained from Oriental Yeast Co., Tokyo, Japan.

is low compared with that of the kidney. However, the hepatic enzyme activity is exceptionally high at birth and is decreased rapidly to the adult level within 1 week after birth (Taniguchi \& Inoue, 1986).

Previous studies suggest that the intra-organ utilization of GSH can occur in the livers of newborn rats and those fed with a $100 \mathrm{~g}$ soya-bean-protein $/ \mathrm{kg}$ diet during weanling, but not in adult rats. The increase in GGT activity in liver is an indication of the hepatic degradation of GSH and utilization of cysteine in neonates. In the present study, we have investigated the ontogenic changes in hepatic levels of GSH, MT and GGT in fetus and newborn rats from pregnant control rats and those fed with a soya-bean-protein diet, low in cysteine content.

\section{METHODS}

Time-pregnant Sprague-Dawley rats (Canadian Breeding Farm and Laboratory, SaintConstant, Quebec, Canada) were housed in individual plastic cages with bedding material in a temperature-controlled room $\left(20-22^{\circ}\right)$ adjusted to $12 \mathrm{~h}$ cycles of light and dark. Starting on day 14 of gestation, rats were fed on a 100 g soya-bean-protein $/ \mathrm{kg}$ diet (Table 1). This diet also has a low sulphur amino acid content (cystine and methionine 0.12 and $0.13 \mathrm{~g} / \mathrm{kg}$ respectively), about $33 \%$ of control Purina rat chow diet. Control rats were fed on a laboratory Purina chow from Agway Prolab diets. The control diet contained 0.32 and $0.43 \mathrm{~g}$ cystine and methionine $/ \mathrm{kg}$ respectively. Both the diets and deionized water were provided ad lib.

Rats were killed by exsanguination under pentobarbital anaesthesia and the livers and kidneys from the fetuses and dams were collected on ice for immediate processing. The pups were decapitated and livers were excised. All the rats were killed in the morning between 09.00 and 12.00 hours for comparison of the GSH levels. The tissue samples (about $100 \mathrm{mg}$ ) were placed in ice-cold trichloroacetic acid $(50 \mathrm{~g} / 1)$ containing $1 \mathrm{~mm}$-EDTA and were homogenized in a Polytron homogenizer (Tecmar Company, Cincinnati, Ohio). The concentrations of GSH in the acid-soluble fractions were determined by the 


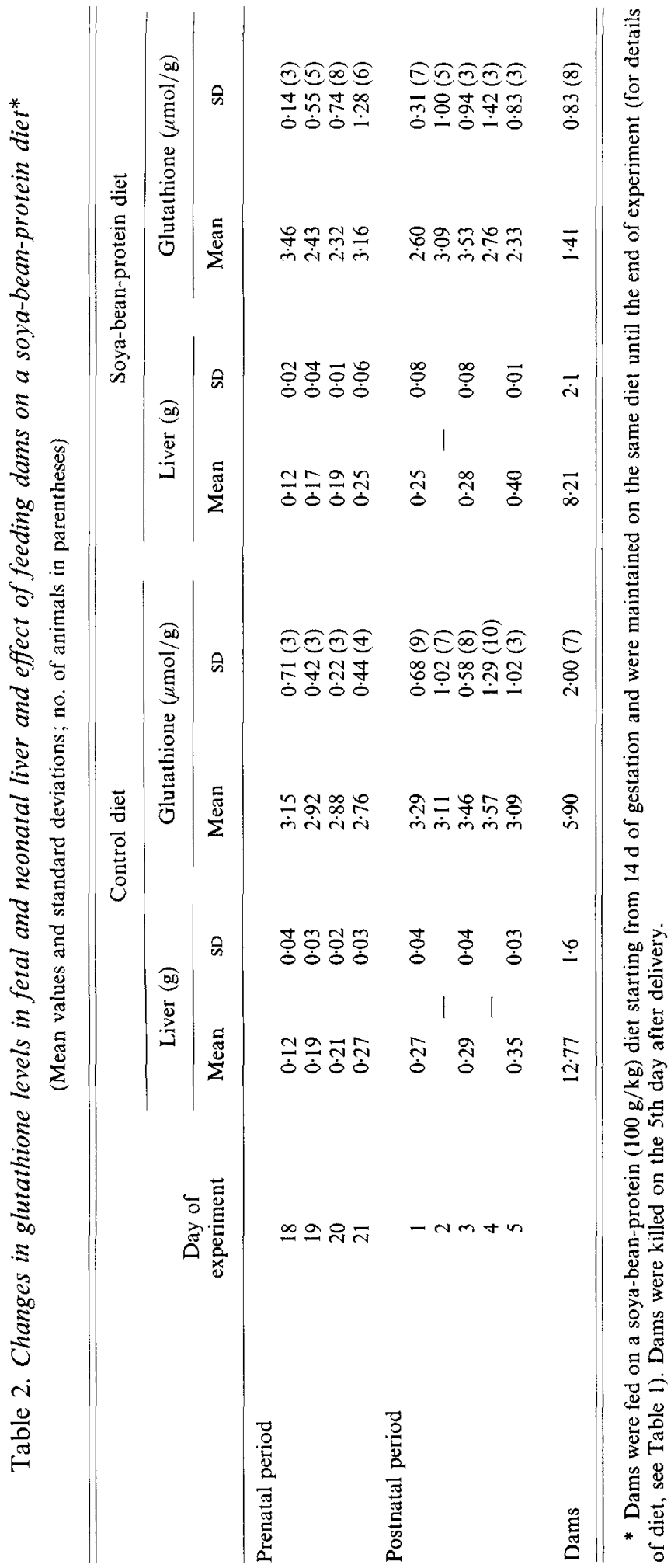


glutathione-reductase dithio-bis (2-nitrobenzoic acid) (DTNB) recycling method of Tietze (1969) after centrifugation of the homogenates, using 1-2 $\mu 1$ of the acid extracts as described previously (Taniguchi \& Inoue, 1986).

The liver samples were frozen in liquid nitrogen and stored at $-80^{\circ}$ until analysed for $\mathrm{MT}, \mathrm{Zn}$ and GGT activity. The concentrations of MT in liver samples were estimated by a cadmium saturation method as described by Onosaka \& Cherian (1982). Tissue samples were digested in nitric acid (trace metal analysis grade) for $24 \mathrm{~h}$ and $\mathrm{Zn}$ levels were measured by atomic absorption spectrophotometry (Spectra-30; Varian, Georgetown, Ontario) using an air-acetylene flame as described elsewhere (Onosaka \& Cherian, 1982). GGT activity was determined by the method of Szasz (1969), following solubilization of the homogenates with Triton X-100 $(10 \mathrm{~g} / 1)$ in $0 \cdot 1 \mathrm{~m}$-Tris hydrochloride buffer, $\mathrm{pH} 8 \cdot 0$. Protein was determined by the method of Lowry et al. (1951), using bovine serum albumin as a standard.

The values were statistically analysed by one-way analysis of variance (ANOVA) together with Student's $t$ test when required.

\section{RESULTS}

Hepatic GSH levels of the dams fed on the soya-bean-protein diet were markedly lower (1.41 (SD 0.49)) than those in control dams (5.90 (SD 2.0)) fed on Purina rat chow (Table 2). The soya-bean-protein diet contained only about $33 \%$ of the sulphur amino acids of the Purina rat chow. In contrast to the livers, GSH levels of the rat kidneys were not affected by soya-bean-protein feeding as was observed previously in growing rats (Taniguchi \& Inoue, 1986).

Dams of the soya-bean-protein-fed group delivered normal pups without any deformity on day 21 of gestation but the sizes of litters (five to eight pups) were small compared with those of eight to twelve pups from the dams of the control group. There was little change in hepatic GSH levels of rat pups throughout the late gestational period, from days 18-21, and the early neonatal period, from birth to $5 \mathrm{~d}$ of age. Although a small decrease in GSH levels was observed in pups from soya-bean-protein-fed dams, these changes were not statistically different from those of the control group, as shown in Table 2.

In contrast to GSH, the levels of $\mathrm{Zn}$ and MT in the livers of the fetuses increased with age and reached a maximum at birth (Fig. 1 $(a$ and $b)$ ). These results are similar to our previous findings (Panemangalore et al. 1983; Templeton et al. 1985). However, there was no significant difference in either MT or Zn levels at any age between the soya-beanprotein-fed and control groups. Both hepatic $\mathrm{Zn}$ and MT levels of the dams were lower than those of the pups and there were no differences in $\mathrm{Zn}$ or MT levels between the two groups of mothers ( $\mathrm{Zn}, 29$ to $32.8 \mu \mathrm{g} / \mathrm{g}$; MT, 22 to $26.5 \mu \mathrm{g} / \mathrm{g}$ liver).

The activity of GGT in the livers of control rat pups reached a maximum at birth and then decreased rapidly to adult levels by $4 \mathrm{~d}$ of age, as shown in Fig. 2. Compared with the control pups, a slower regression in the enzyme activity was observed in the livers of neonates from the dams of the soya-bean-protein group. In the pups from the soya-beanprotein-fed dams, the enzyme activity reached a maximum only $2 \mathrm{~d}$ after birth. The pattern of decline of enzyme activity was also quite different from that of the control group, as shown in Fig. 2.

\section{DISCUSSION}

Glutathione is a major non-protein cysteine reservoir in the liver and is involved in several cellular functions, such as catalysis, transport, metabolism and detoxification of both endogenous and exogenous compounds (Meister \& Anderson, 1983). Thus, GSH is 

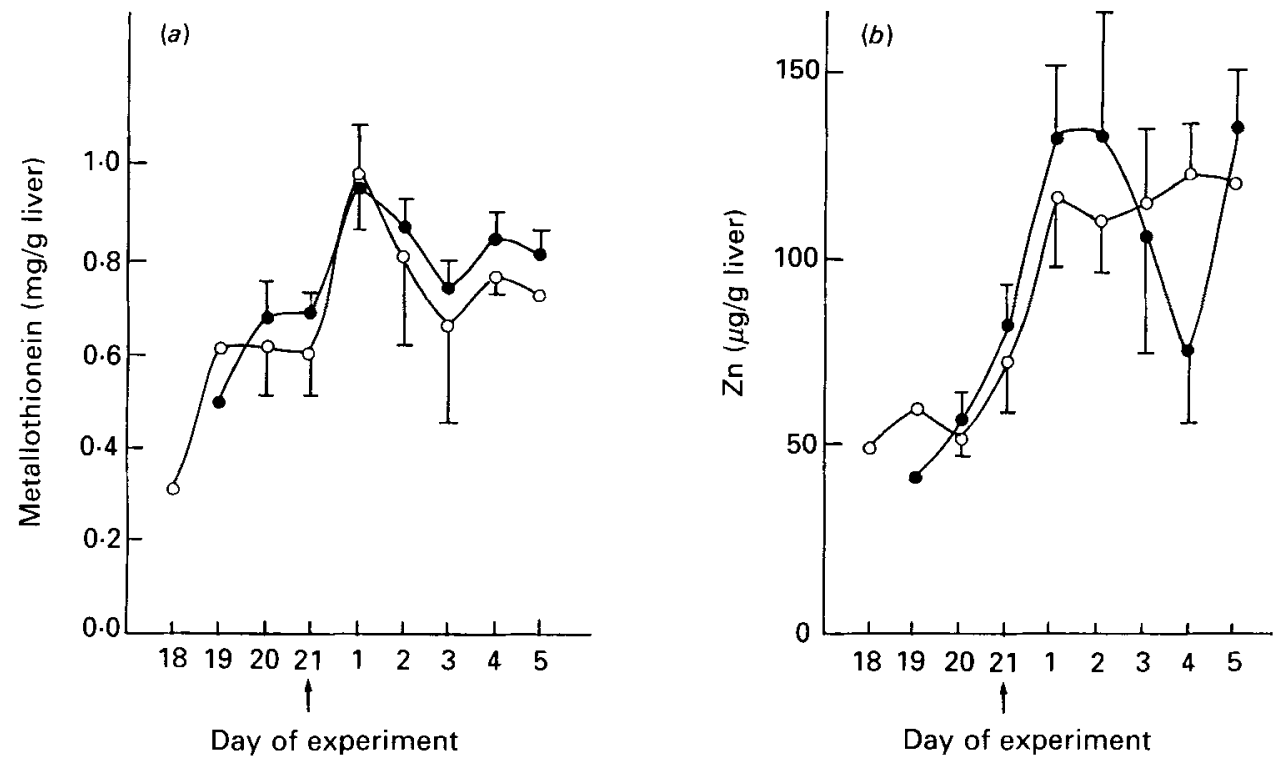

Fig. 1. Developmental changes in hepatic metallothionein $(a)$ and zinc $(b)$ levels in rats. The concentrations of metallothionein and $\mathrm{Zn}$ were measured at different days of the experiment in livers of fetal and neonatal rats from dams fed on control $(O)$ or soya-bean-protein $(O)$ diets. Values are means and standard deviations represented by vertical bars. $\uparrow$ Indicates day of birth.

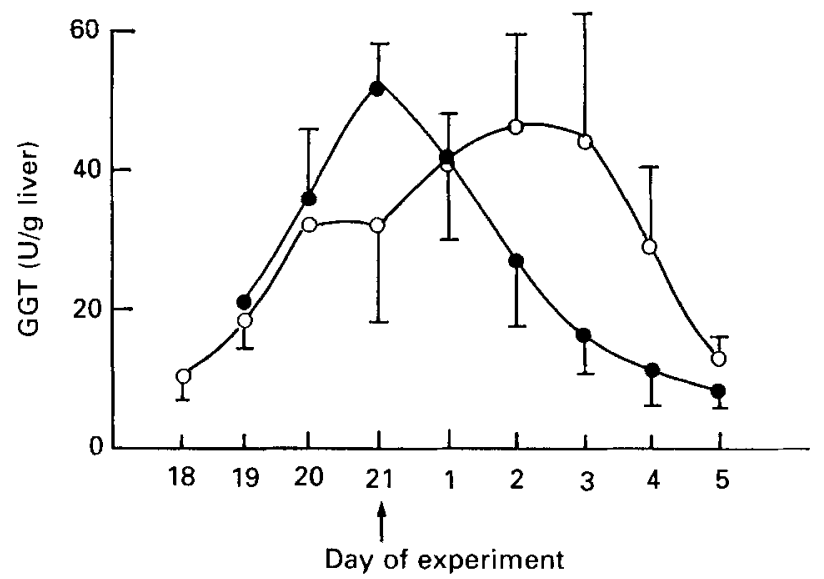

Fig. 2. Hepatic $\gamma$-glutamyltransferase (EC 2.3.2.2; GGT) activity in fetal and newborn rats. The enzyme activity was measured in fetal and neonatal rats from dams fed on control $(O)$ or soya-bean-protein $(O)$ diets and is expressed as enzyme units per g liver. Values are means and standard deviations represented by vertical bars. $\uparrow$ Indicates day of birth.

important in maintaining the structural integrity of the cell and in the synthesis of macromolecules. In mammals, GSH is synthesized intracellularly in liver but is transported to the kidney where it is hydrolysed by the membrane-bound enzyme GGT (Curthoys, 1986; Inoue et al. 1986). There is little degradation of GSH in the adult liver and this supports an inter-organ metabolism of GSH in adult animals as proposed by others (Meister \& Anderson, 1983; Curthoys, 1986; Inoue et al. 1986). Although the synthesis and 
metabolism of GSH has been extensively studied in adult rat liver and kidney, there have been only a few studies (Heinonen, 1973; States et al. 1987) on the regulation of its synthesis and metabolism during perinatal development. In our previous study (Taniguchi \& Inoue, 1986), an intra-organ metabolism of GSH in the liver was proposed in newborn rats based on ontogenic changes in hepatic GSH, GGT activity and estimation of GSH turnover rates. The induction of intra-organ GSH metabolism in the liver was also demonstrated in weanling rats when they were fed on a $100 \mathrm{~g}$ soya-bean-protein $/ \mathrm{kg}$ diet, but no such changes occurred in adult rats (Taniguchi \& Inoue, 1986).

The results of the present study suggest that hepatic GSH levels are markedly decreased in dams fed on a soya-bean-protein diet without affecting the hepatic GSH or MT levels in the fetus and neonates. This can be explained by a continuous supply of cysteine from the mother's blood or milk or by the cystathionase pathway in fetal-neonatal rat liver; nevertheless, dietary supplements of cysteine and methionine to the dams given the soyabean-protein diet were less than $33 \%$ of that from the laboratory chow. The gradual increase in hepatic MT levels with age is related to the accumulation of $\mathrm{Zn}$, as reported earlier (Templeton et al. 1985; Gallant \& Cherian, 1986; Andrews et al. 1987) and not to the GSH level, which is almost unaltered during perinatal development in rats (Taniguchi \& Inoue, 1986; States et al. 1987). On the other hand, alterations in hepatic GGT activity in pups from soya-bean-protein-fed dams suggest increased utilization of intrahepatic cysteine. This may be an adaptive mechanism to compensate for the changes in cysteine metabolism caused by maternal malnutrition. The activities of both enzymes in the glutathione synthetic pathway, glutamate-cysteine ligase (EC 6.3.2.2) and GSH synthetase (EC 6.3.2.3), are low in fetal and neonatal rat livers (Higashi \& Tateishi, 1978) and increase with age. Thus, the hepatic GSH levels of rats during perinatal development may be controlled mainly by these enzymes and not by cysteine levels.

The limited supply of cysteine and methionine from dams to pups may effect a delay in the maturation of intrahepatic GSH metabolism in neonates to the inter-organ metabolism of the adult type, as indicated by a delayed expression of hepatic GGT in pups from soyabean-protein-fed dams as compared with control pups (Fig. 2). Thus, the continued presence of high hepatic GGT activity in such pups during a few additional days after birth will facilitate the utilization of cysteine.

A previous study (Sakamoto et al. 1983) showed that injection of pregnant mice with hydrocortisone increased the GGT activity in fetal livers at an earlier time-period. Thus, the alteration in the appearance of the hepatic enzyme activity in the present experiment can be explained by changes in secretion of an endocrine hormone from the sulphhydryl-deficient dam or in development of its receptor in the fetus, or both. Further studies are needed to elucidate the mechanism of altered enzyme expression of fetuses under stress conditions induced by nutritional deficiencies. Measurement of blood hydrocortisone levels may provide some useful information.

During fetal development, the hepatic concentration of MT, unlike that of GSH, increases in rats, reaching maximum levels at birth. MT contains about $30 \%$ cysteine, and in the livers of newborn rats the total amount of cysteine present in MT is almost equal to that in GSH. Although the exact cysteine source for the synthesis of GSH and MT in newborn rat liver is not yet understood, both these thiol-containing peptides can be effectively synthesized in hepatocytes, even when hepatic GSH levels in the dams are low and thus limiting, and in the absence of active supply of sulphur amino acids from dams. In contrast to GSH, the levels of hepatic MT in newborn rats are regulated mainly by accumulation of $\mathrm{Zn}$, and MT levels are markedly decreased when the dams are fed on $\mathrm{Zn}$ deficient diet during late gestation (Gallant \& Cherian, 1986; Andrews et al. 1987). 
This work was supported by research grants from the Medical Research Council of Canada. The authors wish to acknowledge the competent technical assistance of Miss Susanne Bormann.

\section{REFERENCES}

Andrews, G., Gallant, K. R. \& Cherian, M. G. (1987). Regulation of the ontogeny of rat liver metallothionein mRNA by zinc. European Journal of Biochemistry 166, 527-531.

Bell, J. U. (1979). Native metallothionein levels in rat hepatic cytosol during perinatal development. Toxicology and Applied Pharmacology 50, 101-107.

Curthoys, N. P. (1986). Interorgan flux of glutathione. Federation Proceedings, 45, 2166-2169.

Gallant, K. R. \& Cherian, M. G. (1986). Influence of maternal mineral deficiency on the hepatic metallothionein and zinc in newborn rats. Biochemistry and Cell Biology 64, 8-12.

Gaull, G., Sturman, J. A. \& Räihä, N. C. R. (1972). Development of mammalian sulfur metabolism: Absence of cystathionase in human fetal tissues. Pediatric Research 6, 538-547.

Heinonen, K. (1973). Studies on cystathionase activity in rat liver and brain during development. Biochemistry Journal 136, 1011-1015.

Higashi, T. \& Tateishi, N. (1978). Physiological significance of elevation of liver $\gamma$-glutamyltranspeptidase in late pregnancy. In Function of Glutathione in Liver and Kidney, pp. 22-26 [H. Sies and A. Wendel, editors]. Amsterdam: Springer.

Inoue, M. \& Morino, Y. (1981). Inactivation of renal $\gamma$-glutamyltransferase by 6-diazo-5 oxo-L-nonleucyl glycine, an inactive precursor of affinity labelling reagent inactivates $\gamma$-glutamyltransferase. Proceedings of the National Academy of Sciences, USA 78, 46-49.

Inoue, M., Shinozuka, S. \& Morino, Y. (1986). Mechanism of renal peritubular extraction of plasma glutathione. European Journal of Biochemistry 157, 605-609.

Kaplowitz, N., Aw, T. Y. \& Ookhtens, M. (1985). The regulation of hepatic glutathione. Annual Review of Pharmacology and Toxicology 25, 715-744.

Lowry, O. H., Rosebrough, N. J., Farr, A. L. \& Randall, R. J. (1951). Protein measurement with the Folin phenol reagent. Joumal of Biological Chemistry 193, 265-275.

McIntyre, T. M. \& Curthoys, N. P. (1979). Comparison of the hydrolytic and transfer activities of rat renal $\gamma$ glutamyl-transpeptidase. Journal of Biological Chemistry 254, 6499-6504.

Meister, A. \& Anderson, M. E. (1983). Glutathione. Annual Review of Biochemistry 52, 711-760.

Onosaka, S. \& Cherian, M. G. (1982). Comparison of metallothionein determination by polarographic and cadmium saturation methods. Toxicology and Applied Pharmacology 63, 270-274.

Panemangalore, M., Banerjee, D., Onosaka, S. \& Cherian, M. G. (1983). Changes in the intracellular accumulation and distribution of metallothionein in rat liver and kidney during postnatal development. Developmental Biology 97, 95-102

Rogers, Q. R. \& Harper, A. E. (1965). Amino acid diets and maximal growth in the rat. Journal of Nutrition 87. $267-273$

Sakamoto, Y., Higashi, T. \& Tateishi, N. (1983). Factors involved in the appearance and switch-off of hepatic $\gamma$ glutamyl transpeptidase. Gann Monograph on Cancer Research 29, 281-288.

States, B., Foreman, J. W. \& Segal, S. (1987). Cysteine and glutathione levels in developing rat kidney and liver. Pediatric Research 22, 605-608.

Szasz, G. (1969). A kinetic photometric method for serum $\gamma$-glutamyl-transpeptidase. Clinical Chemistry 15, $124-136$

Taniguchi, M. \& Inoue, M. (1986). Ontogenic changes in metabolism and transport of glutathione in the rat. Journal of Biochemistry 100, 1457-1463.

Tateishi, N., Higashi, T., Naruse, A., Nakashima, K., Shiozaki, H. \& Sakamoto, Y. (1977). Rat liver glutathione: Possible role as a reservoir of cysteine. Journal of Nutrition 107, 51-60.

Tateishi, N., Higashi, T., Shinya, S., Naruse, A. \& Sakamoto, Y. (1974). Studies on the regulation of glutathione level in rat liver. Journal of Biochemistry 75, 93-104.

Templeton, D. M., Banerjee, D. \& Cherian, M. G. (1985). Metallothionein synthesis and localization in relation to metal storage in rat liver during gestation. Canadian Journal of Biochemistry and Cell Biology 63, 16-22.

Tietze, F. (1969). Enzymic method for quantitative determination of nanogram amounts of total and oxidized glutathione. Analytical Biochemistry 27, 502-522.

Wong, K. \& Klaassen, C. D. (1979). Isolation and characterization of metallothionein which is highly concentrated in newborn rat liver. Journal of Biological Chemistry 254, 12399-12403.

Zlotkin, S. H. \& Anderson, G. H. (1982). The development of cystathionase activity during the first year of life. Pediatric Research 16, 65-68. 